\section{Sociocognitive Conflict Regulation: How to Make Sense of Diverging Ideas}

\author{
Fabrizio Butera ${ }^{1}$ D, Nicolas Sommet ${ }^{2}$, and Céline Darnon ${ }^{3}$ \\ ${ }^{1}$ Institute of Psychology, University of Lausanne; ${ }^{2}$ Life Course and Inequality Research Centre (LINES), \\ University of Lausanne; and ${ }^{3}$ Laboratory of Social and Cognitive Psychology, Centre National de la \\ Recherche Scientifique (CNRS), University of Clermont Auvergne
}

Current Directions in Psychological Science

2019, Vol. 28(2) 145-151

(C) The Author(s) 2019

Article reuse guidelines: sagepub.com/journals-permissions DOI: $10.1177 / 0963721418813986$ www.psychologicalscience.org/CDPS (9SAGE

\begin{abstract}
Sociocognitive conflict arises when people hold different views or ideas about the same object, and it has the potential to promote learning, cognitive development, and positive social relations. The promotion of these outcomes, however, depends on how the conflict is regulated and with what goals: Mastery goals predict epistemic conflict regulation and the elaboration of multiple ideas, performance-approach goals predict competitive conflict regulation and the promotion of one's own ideas, and performance-avoidance goals predict protective conflict regulation and yielding to other people's ideas. Conflict regulation thus determines the conditions under which confronting diverging ideas results in positive cognitive and relational outcomes.
\end{abstract}

\title{
Keywords
}

sociocognitive conflict, conflict regulation, achievement goals, learning, cognitive development

The concept of conflict has a lengthy history in psychological science, albeit with different interpretations. From early studies on intergroup conflict (Sherif, 1966) to more recent work on oppression (Sidanius \& Pratto, 2001), social psychology has traditionally focused on destructive conflicts (Sommet, Quiamzade, \& Butera, 2017) based on competition between individuals and between groups. On the contrary, from Piaget's studies on the equilibration of cognitive structures (1975/1985) to work on conceptual change (Chi, 2008), cognitive psychology and the learning sciences have focused on constructive conflicts based on individual exposure to contradictory information (Limón, 2001). The present article presents the integrative framework of sociocognitive conflict stemming from research on sociocognitive development (Doise \& Mugny, 1984) and social influence (Pérez \& Mugny, 1996). This line of research has demonstrated that conflict can be either constructive or destructive depending on the way it is regulated (Butera, Darnon, \& Mugny, 2011).

\section{The Concept of Sociocognitive Conflict}

The concept of sociocognitive conflict was introduced by Mugny and Doise (1978) and Doise and Mugny (1984) to account for the finding that children interacting with others are more likely to progress on a task than children working alone. This work was based on Piaget's concept of cognitive conflict (Piaget, 1975/1985), which arises when a child's cognitive structures are disrupted by new and inconsistent information. The disequilibrium that ensues requires some adjustment in the child's cognitive structures, which leads to more elaborate knowledge and cognitive gains. Very often, however, direct information from the object is not available or is misleading, cognitive conflict does not take place, and people may carry on with false or suboptimal knowledge.

Doise and Mugny (1984) reasoned that children reach a higher level of cognitive development when interacting with others than when working alone because the disequilibrium may come from the divergent point of view of their partner. The disruption of previous knowledge by a dissenting partner is called sociocognitive conflict. This conflict requires some adjustment and may thereby result in more elaborate knowledge. The constructive effects of such conflictual interactions have been documented in dozens of

\section{Corresponding Author:}

Fabrizio Butera, University of Lausanne, Institute of Psychology and Faculty of Social and Political Sciences, Géopolis, CH 1015 Lausanne, Switzerland

E-mail: fabrizio.butera@unil.ch 
experiments with children (Doise \& Mugny, 1984) and adults (Darnon, Buchs, \& Butera, 2002), replicated by other laboratories (Ames \& Murray, 1982), and extended to the realm of professional and political decision making (see Johnson's, 2015, work on "constructive controversy") and interactions in computer-supported collaborative learning groups (see Kapur's, 2008, work on "productive failure").

Importantly, the observed progress is accounted for by conflict and not merely by interaction: Mugny and Doise (1978) showed that interaction led to progress even when a child interacted with a partner who had a lower level of cognitive development, which is inconsistent with an explanation in terms of the mere transfer of competences. Later, Doise and Mugny (1979) showed that interindividual conflict (between two children with opposing viewpoints) led to greater cognitive progress than intraindividual conflict (each child experiencing two viewpoints).

\section{From Conflict to Conflict Regulation}

Conflict per se is an experience. After direct perception or communication, an individual realizes that there is a discrepancy, a conflict between his or her existing knowledge, interpretation, or point of view and the knowledge, interpretation, or point of view of another. An experience then needs a process to be "guided" to behavior: There must be some self-regulation to determine which behavior one wants or does not want to engage in after some experience (Carver \& Scheier, 2001).

In this respect, research on sociocognitive conflict has shown that faced with a diverging point of view, people may be puzzled and start wondering why the other person holds a different view. Conflict raises doubts about the validity of one's point of view (e.g., "Is my answer correct?"), which may lead to decentering from one's own perspective, taking into account the other person's position, and trying to integrate the two (Butera \& Buchs, 2005). If this integration succeeds, one may end up with new knowledge that is more complex and more adapted than the single individual positions. But conflict also raises doubts about one's relative competence (e.g., "Am I right or wrong?"), which may lead to defending one's competence by either sticking to one's own opinion or deferring to the disagreeing other person.

Thus, because sociocognitive conflict has both a cognitive (focused on the task) and a social (focused on social comparison) component, scholars who have worked in this field do not use the term self-regulation, which refers to intraindividual processes, and prefer to use the term conflict regulation. Conflict regulation is thus the meaning that people attribute to conflict when facing another person's idea that contradicts their own.

\section{Varieties of Sociocognitive Conflict Regulation}

Sociocognitive conflict may result in various outcomes (see Butera \& Darnon, 2017) and thus may be regulated in various ways (see Fig. 1).

Epistemic conflict regulation is the meaning that people attribute to sociocognitive conflict when they focus on the task and the validity of their and the partner's position. The cognitive component of the conflict prevails, and the regulation caters to the discrepancy between two positions rather than the opposition between two persons. Conflicting partners are thus concerned with making sense of an epistemic riddle that pertains to the existence of one object and two different answers. This exploration and coordination of existing and supplementary evidence triggers the constructive effects of epistemic conflict regulation (Quiamzade, Mugny, \& Darnon, 2009).

If the social component of conflict prevails, then the regulation caters to the opposition between two persons rather than ideas. Task processing suffers from such relational conflict regulation, as do performance and cognitive development. Recent research has documented the processes involved in relational conflict regulation and revealed a further distinction (Sommet et al., 2014).

Competitive relational conflict regulation is the meaning that people attribute to sociocognitive conflict when they focus on the relational component of conflict, social comparison, and, in particular, the intractable nature of disagreement: One must be right and the other wrong. As being right affords status, partners stick to their own position, assuming that the other is wrong (Quiamzade \& Mugny, 2009).

Protective relational conflict regulation is the meaning that people attribute to sociocognitive conflict when they focus on the relational component of conflict, social comparison, and, in particular, self-inferiority: One thinks the other is probably more correct than oneself. Again, in such situation one's self-evaluation is at risk of being negative because being wrong is highly likely; regulatory strategies are then directed toward adopting the other's point of view in a form of compliance.

Two sets of results support the above conceptual distinctions. First, these three constructs were operationalized using a conflict-regulation scale (see Table 1), and respondents indeed considered them as separate forms of regulation. Darnon, Muller, Schrager, Pannuzzo, and Butera (2006, Study 1) asked participants to imagine a 


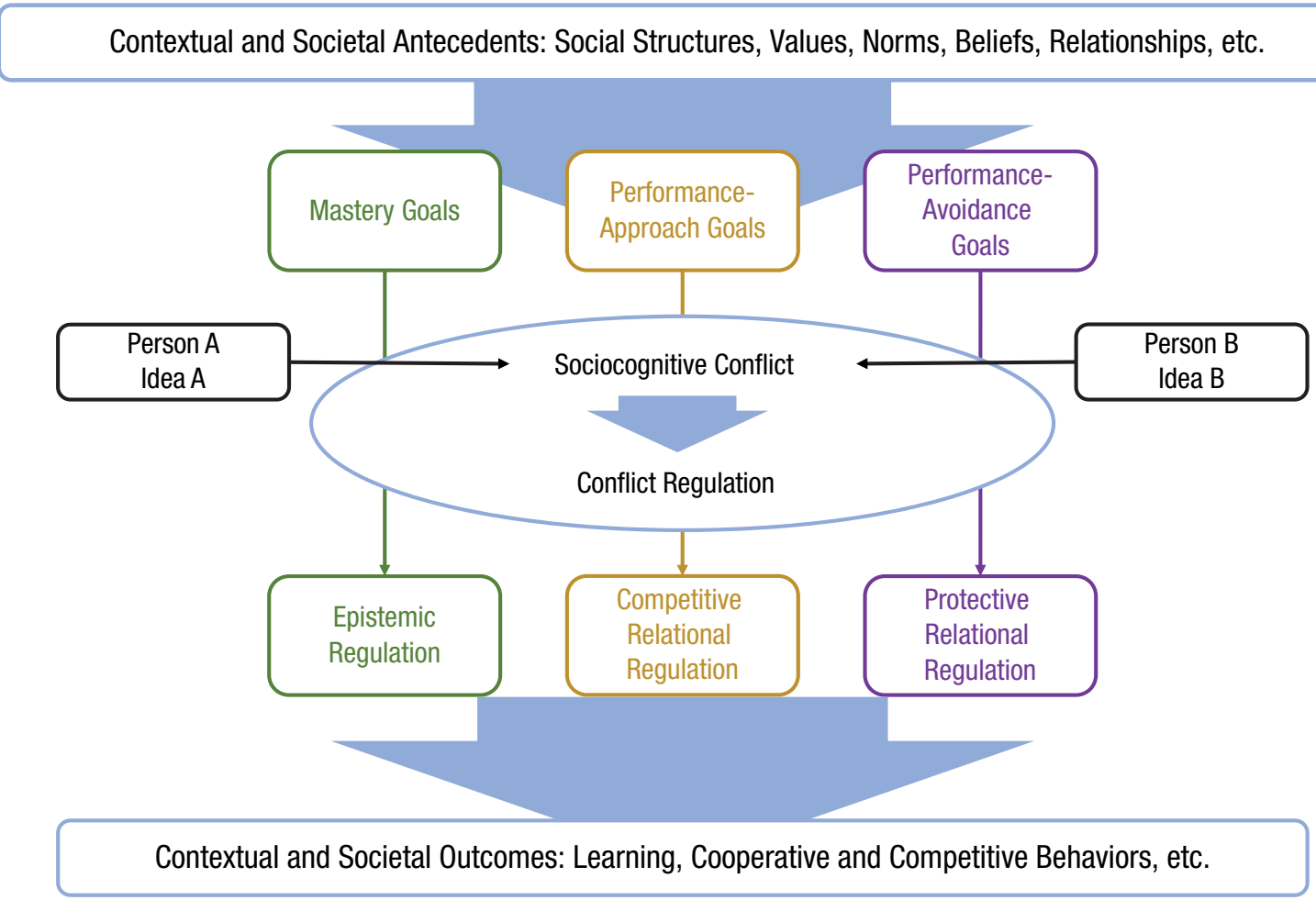

Fig. 1. The regulation of sociocognitive conflict. Sociocognitive conflict emerges when interacting persons hold diverging ideas. The effects of sociocognitive conflict on contextual and societal outcomes, such as learning, depend on the way conflict is regulated, namely in an epistemic, competitive relational, or protective relational way. Which form of conflict regulation takes place depends on the situational or dispositional achievement goals adopted during the interaction. These goals are mastery (the desire to master the task), performance approach (the desire to outperform the other person), and performance avoidance (the desire to not be outperformed by the other person).

discussion with someone who disagrees with them and how they would regulate such a conflict. The scale included items for both epistemic and competitive conflict regulation, which appeared to correspond to two separate components. Sommet et al. (2014, Study 3) later compared competitive and protective conflict regulation and found that they indeed loaded on separate components.

The second set of results pertains to the relation between conflict regulation and learning. Doise and
Mugny (1984) observed that interacting with a disagreeing partner led to greater progress than working alone, provided that partners could actually confront each other and discuss their points of view (see also Psaltis \& Duveen, 2006). Darnon, Doll, and Butera (2007) reported more direct, experimental evidence in a study in which dyads of students were asked to read a text and exchange their answers during a computermediated learning session. In fact, each member of the

Table 1. Items Used to Assess Self-Reported Sociocognitive Conflict Regulation (From Darnon, Muller, Schrager, Pannuzzo, \& Butera, 2006; Sommet et al., 2014)

Item:

Conflict-regulation strategy $\quad$ When disagreements occurred, to what extent did you ...

$\begin{array}{ll}\text { Epistemic } & \text { - Try to think about the text again in order to understand better? } \\ & \text { - Try to examine the conditions under which each point of view could help you understand? } \\ \text { Competitive relational } & \text { - Try to think of a solution that could integrate both points of view? } \\ \text { - Try to show your partner was wrong? } & \text { - Try to show you were right? } \\ \text { Protective relational } & \text { - Think your partner was certainly more correct than you? } \\ & \text { - Comply with his/her proposition? }\end{array}$


dyads received bogus feedback in which the alleged partner disagreed. In an epistemic-conflict condition, the partner's disagreement focused on content (e.g., "I wonder whether the answer should be ..."), whereas in a competitive-relational-conflict condition, the focus was on the participant's self-competence (e.g., "I think you are wrong. The answer is ..."). The results revealed that participants obtained better results on a learning test when they were confronted with a partner who regulated conflict in an epistemic rather than a relational way.

\section{Achievement Goals as Predictors of Conflict Regulation}

We have ascertained that conflict regulation shapes cognition and guides behaviors during and after the experience of conflict. But what predicts the way in which conflict will be regulated? Because sociocognitive conflict regulation is a regulatory process focused on acquiring or demonstrating competence, we studied the predictive role of one's purpose of action in competence-relevant situations: achievement goals (Elliot \& McGregor, 2001). Interestingly, achievement goals are divided in a way that parallels the distinctions within conflict regulation. Mastery goals refer to the desire to master the task, to learn and grow, whereas performance goals refer to the desire to demonstrate competence relative to other people. Specifically, performance-approach goals focus on outperforming other people, whereas performance-avoidance goals focus on not being outperformed by other people (for further distinctions, see Elliot \& McGregor, 2001; Elliot, Murayama, \& Pekrun, 2011). It is thus possible that (a) mastery goals predict epistemic conflict regulation because they orient learners to understanding and perceiving people who disagree with them as informational support (integration of information); (b) performance-approach goals predict competitive conflict regulation because they orient learners to establishing their own superiority and perceiving people who disagree with them as opponents (self-confirmation); and (c) performance-avoidance goals predict protective conflict regulation because they orient learners to avoiding inferiority and perceiving people who disagree with them as threats to be avoided (compliance; Fig. 1).

Darnon et al. (2006, Study 1) provided support for the first two hypotheses. They found that mastery goals predicted epistemic conflict regulation and that performance-approach goals predicted competitive conflict regulation. Darnon and Butera (2007) then provided experimental evidence for these effects: The level of perceived conflict was a more positive predictor of epistemic regulation when mastery goals were induced than when performance goals or no goals were induced. Moreover, the level of perceived conflict was a more positive predictor of competitive regulation when performance goals were induced. Darnon, Butera, and Harackiewicz (2007) further demonstrated that participants who interacted with a disagreeing partner obtained higher scores on a measure of learning outcome when mastery goals where induced than when performance-approach goals or no goals were induced; when participants interacted with an agreeing partner, no such difference was observed (see Table 2 for instructions).

As for the distinction between performance-approach and performance-avoidance goals, Sommet et al. (2014, Study 3) showed that the level of perceived conflict was a more positive predictor of competitive relational regulation when performance-approach goals were experimentally induced, whereas it was a more positive predictor of protective relational regulation when performance-avoidance goals were induced. Moreover,

Table 2. Instructions Used to Manipulate Achievement Goals (From Darnon, Harackiewicz, Butera, Mugny, \& Quiamzade, 2007; Darnon, Muller, Schrager, Pannuzzo, \& Butera, 2006)

Achievement goal

Mastery

Performance-approach

Performance-avoidance
Instructions

"It is very important for you to accurately understand the aims of this experiment. You are here to acquire new knowledge that could be useful to you, to understand correctly the experiments and the ideas developed in the text, and to discover new concepts. In other words, you are here to learn."

"The experimenters will evaluate your performance. It is important for you to perform well and obtain a good grade on the different tasks presented here. You should know that a lot of students will do this task. You are asked to keep in mind that you should try to distinguish yourself positively, that is, to perform better than the majority of students. In other words, what we ask you here is to show your competencies, your abilities."

"The experimenters will evaluate your performance. It is important for you to avoid performing poorly and not obtain a bad grade on the different tasks presented here. You should know that a lot of students will do this task. You are asked to keep in mind that you should try not to distinguish yourself negatively, that is, try not to perform more poorly than the majority of students. In other words, what we ask you here is to avoid performing poorly." 
the relationships between performance-approach goals and competitive relational regulation, as well as those between performance-avoidance and protective relational regulation, were found to be stronger when individuals interacted with more competent partners, that is, when the partners represented a potential threat in terms of self-competence (Sommet, Darnon, \& Butera, 2015). These effects were found with conflict-regulation scales and behavioral measures of conflict regulation. Finally, Darnon, Harackiewicz, Butera, Mugny, and Quiamzade (2007) observed that no learning benefits emerge from performance goals in a situation of sociocognitive conflict. The authors showed that manipulated performance-approach goals yielded better learning outcomes than performance-avoidance goals when interacting with an agreeing partner (a classic effect; see Murayama \& Elliot, 2012); however, both goals yielded poor outcomes when an individual interacted with a disagreeing partner.

\section{Conclusions and Future Research}

The work on sociocognitive conflict has uncovered the constructive effects of interacting with individuals who hold different views, and research on conflict regulation has specified the conditions under which conflict may be constructive. Specifically, inducing mastery goals revealed a promising way to reap the benefits of conflict in terms of learning and cognitive development. A recommendation for practitioners (teachers, trainers, coaches) working in environments in which disagreement is likely to emerge would be to provide a climate that fosters mastery goals and favors epistemic conflict regulation. Importantly, the model derived from the present research (Fig. 1) contributes to our understanding of sociocognitive conflict and its regulation but also of the role of conflict in society. Two lines of research can stem from this model.

The first pertains to the consequences of conflict regulation. Epistemic conflict regulation not only yields more positive learning outcomes than relational regulation but also affects the quality of interpersonal relations. For instance, compared with relational regulation (both competitive and protective), epistemic regulation increases the perceived quality of the relationship with the partner, the perceived importance of the partner's contribution, and the recognition of the partner's competence (Darnon et al., 2002, 2006; Darnon, Doll, \& Butera, 2007). Moreover, conflict regulation has been studied in relation to the development of cognitive structures in children as a function of socioeconomic background (Doise \& Mugny, 1984) and the refinement of existing pedagogical tools (e.g., the "jigsaw classroom"; see Roseth, Lee, \& Saltarelli, 2019). Future research should expand the range of cognitive, affective, behavioral, and relational consequences of conflict regulation. In this respect, a fruitful avenue would be to work in relation with cognate conceptualizations, such as dissent in group decision making (Schulz-Hardt, Jochims, \& Frey, 2002), intragroup conflict in organizational psychology (Jehn, 1995), conflict management in team performance (De Dreu \& Weingart, 2003), constructive controversy in cooperative learning (Johnson, 2015), and argumentation in the learning sciences (Asterhan, 2018). In the meantime, an important contribution of the work on sociocognitive conflict to other existing bodies of research is the distinction between conflict and conflict regulation, which makes it possible to specify when and why conflict may or may not result in positive effects.

The second line of future research pertains to the antecedents of conflict regulation. Poortvliet and Darnon (2010) have noted that achievement goals emerge in a network of social relations, norms, and values. Mastery goals, for instance, have been shown to be promoted by a supportive and cooperative classroom climate (C. Ames, 1992). Moreover, self-enhancement values (based on power, wealth, and success) have been related to performance-approach goals (Pulfrey \& Butera, 2013), whereas evaluative educational structures such as grading have been related to performanceavoidance goals (Pulfrey, Buchs, \& Butera, 2011). Future research should thus be concerned with how to advise decision makers and how targeted social policies may trickle down to achievement goals, conflict regulation, and learning. The final aim would be to take advantage of the positive effects of the epistemic regulation of sociocognitive conflict in educational, professional, and societal contexts.

\section{Recommended Reading}

Butera, F., \& Darnon, C. (2017). (See References). Discusses sociocognitive conflict within the wider area of competence assessment.

Doise, W., \& Mugny, G. (1984). (See References). Reviews the early studies on sociocognitive conflict.

Johnson, D. W. (2015). (See References). Reviews the work on constructive controversy in educational, organizational, and political settings.

\section{Action Editor}

Randall W. Engle served as action editor for this article.

\section{ORCID iD}

Fabrizio Butera (iD) https://orcid.org/0000-0002-8856-4374 


\section{Declaration of Conflicting Interests}

The author(s) declared that there were no conflicts of interest with respect to the authorship or the publication of this article.

\section{Funding}

This preparation of this article was supported by the Swiss National Science Foundation.

\section{References}

Ames, C. (1992). Classrooms: Goals, structures, and student motivation. Journal of Educational Psychology, 84, 261271.

Ames, G. J., \& Murray, F. B. (1982). When two wrongs make a right: Promoting cognitive change by social conflict. Developmental Psychology, 18, 894-897.

Asterhan, C. S. (2018). Exploring enablers and inhibitors of productive peer argumentation: The role of individual achievement goals and of gender. Contemporary Educational Psychology, 54, 66-78.

Butera, F., \& Buchs, C. (2005). Reasoning together: From focusing to decentring. In V. Girotto \& P. N. JohnsonLaird (Eds.), The shape of reason: Essays in honour of Paolo Legrenzi (pp. 193-203). Hove, England: Psychology Press.

Butera, F., \& Darnon, C. (2017). Competence assessment, social comparison, and conflict regulation. In A. J. Elliot, C. S. Dweck, \& D. S. Yeager (Eds.), Handbook of competence and motivation: Theory and Application (2nd ed., pp. 192-213). New York, NY: Guilford Press.

Butera, F., Darnon, C., \& Mugny, G. (2011). Learning from conflict. In J. Jetten \& M. Hornsey (Eds.), Rebels in groups: Dissent, deviance, difference and defiance (pp. 36-53). Oxford, England: Wiley-Blackwell.

Carver, C. S., \& Scheier, M. F. (2001). On the self-regulation of behavior. Cambridge, England: Cambridge University Press.

Chi, M. T. H. (2008). Three types of conceptual change: Belief revision, mental model transformation, and categorical shift. In S. Vosniadou (Ed.), International handbook of research on conceptual change (pp. 61-82). New York, NY: Routledge.

Darnon, C., Buchs, C., \& Butera, F. (2002). Epistemic and relational conflict in sharing information during cooperative learning. Swiss Journal of Psychology, 61, 139-151.

Darnon, C., \& Butera, F. (2007). Learning or succeeding? Conflict regulation with mastery or performance goals. Swiss Journal of Psychology, 66, 145-152.

Darnon, C., Butera, F., \& Harackiewicz, J. M. (2007). Achievement goals in social interactions: Learning with mastery vs. performance goals. Motivation and Emotion, 31, 61-70.

Darnon, C., Doll, S., \& Butera, F. (2007). Dealing with a disagreeing partner: Relational and epistemic conflict elaboration. European Journal of Psychology of Education, $22,227-242$.

Darnon, C., Harackiewicz, J., Butera, F., Mugny, G., \& Quiamzade, A. (2007). Performance-approach and performance-avoidance goals: When uncertainty makes a difference. Personality and Social Psychology Bulletin, 33, 813-827.

Darnon, C., Muller, D., Schrager, S., Pannuzzo, N., \& Butera, F. (2006). Mastery and performance goals predict epistemic and relational conflict regulation. Journal of Educational Psychology, 98, 766-776.

De Dreu, C. K., \& Weingart, L. R. (2003). Task versus relationship conflict, team performance, and team member satisfaction: A meta-analysis. Journal of Applied Psychology, 88, 741-749.

Doise, W., \& Mugny, G. (1979). Individual and collective conflicts of centrations in cognitive development. European Journal of Social Psychology, 9, 105-108.

Doise, W., \& Mugny, G. (1984). The social development of the intellect. Oxford, England: Pergamon Press.

Elliot, A. J., \& McGregor, H. A. (2001). A $2 \times 2$ achievement goal framework. Journal of Personality and Social Psychology, 80, 501-519.

Elliot, A. J., Murayama, K., \& Pekrun, R. (2011). A $3 \times 2$ achievement goal model. Journal of Educational Psychology, 103, 632-648.

Jehn, K. A. (1995). A multimethod examination of the benefits and detriments of intragroup conflict. Administrative Science Quarterly, 40, 256-282.

Johnson, D. W. (2015). Constructive controversy: Theory, research, practice. Cambridge, England: Cambridge University Press.

Kapur, M. (2008). Productive failure. Cognition and Instruction, 26, 379-424.

Limón, M. (2001). On the cognitive conflict as an instructional strategy for conceptual change: A critical appraisal. Learning and Instruction, 11, 357-380.

Mugny, G., \& Doise, W. (1978). Socio-cognitive conflict and structure of individual and collective performances. European Journal of Social Psychology, 8, 181-192.

Murayama, K., \& Elliot, A. J. (2012). The competitionperformance relation: A meta-analytic review and test of the opposing processes model of competition and performance. Psychological Bulletin, 138, 1035-1070.

Pérez, J. A., \& Mugny, G. (1996). The conflict elaboration theory of social influence. In E. Witte \& J. H. Davis (Eds.), Understanding group behavior, Volume 2: Small group processes and interpersonal relations (pp. 191-210). Hillsdale, NJ: Erlbaum.

Piaget, J. (1985). The equilibration of cognitive structures: The central problem of intellectual development. Chicago, IL: University of Chicago Press. (Original work published 1975)

Poortvliet, P. M., \& Darnon, C. (2010). Toward a more social understanding of achievement goals: The interpersonal effects of mastery and performance goals. Current Directions in Psychological Science, 19, 324-328.

Psaltis, C., \& Duveen, G. (2006). Social relations and cognitive development: The influence of conversation type and representations of gender. European Journal of Social Psychology, 36, 407-430.

Pulfrey, C., Buchs, C., \& Butera, F. (2011). Why grades engender performance-avoidance goals: The mediating role of autonomous motivation. Journal of Educational Psychology, 103, 683-700. 
Pulfrey, C., \& Butera, F. (2013). Why neoliberal values of self-enhancement lead to cheating in higher education: A motivational account. Psychological Science, 24, 21532162.

Quiamzade, A., \& Mugny, G. (2009). Social influence and threat in confrontations between competent peers. Journal of Personality and Social Psychology, 97, 652666.

Quiamzade, A., Mugny, G., \& Darnon, C. (2009). The coordination of problem solving strategies: When low competence sources exert more influence on task processing than high competence sources. British Journal of Social Psychology, 48, 159-182.

Roseth, C. J., Lee, Y., \& Saltarelli, W. A. (2019). Reconsidering jigsaw social psychology: Longitudinal effects on social interdependence, sociocognitive conflict regulation, motivation, and achievement. Journal of Educational Psychology, 111, 149-169. doi:10.1037/edu0000257

Schulz-Hardt, S., Jochims, M., \& Frey, D. (2002). Productive conflict in group decision making: Genuine and contrived dissent as strategies to counteract biased information seeking. Organizational Behavior and Human Decision Processes, 88, 563-586.

Sherif, M. (1966). In common predicament: Social psychology of intergroup conflict and cooperation. Boston, MA: Houghton Mifflin.

Sidanius, J., \& Pratto, F. (2001). Social dominance: An intergroup theory of social bierarchy and oppression. Cambridge, England: Cambridge University Press.

Sommet, N., Darnon, C., \& Butera, F. (2015). To confirm or to conform? Performance goals as a regulator of conflict with more competent others. Journal of Educational Psychology, 107, 580-598.

Sommet, N., Darnon, C., Mugny, G., Quiamzade, A., Pulfrey, C., Dompnier, B., \& Butera, F. (2014). Performance goals in conflictual social interactions: Toward the distinction between two modes of relational conflict regulation. British Journal of Social Psychology, 53, 134-153.

Sommet, N., Quiamzade, A., \& Butera, F. (2017). How would Pyrrho have been socially valued? Social desirability and social utility of conflict regulation. International Review of Social Psychology, 30, 141-148. 